Удк 330.35

D.Y. Salko

\section{ANALYSIS OF THE DEVELOPMENT OF INNOVATION MANAGEMENT CONCEPTS}

The article discusses and analyzes various concepts of innovation management in different periods of time. Their features, advantages and disadvantages are revealed. $\mathrm{A}$ chronological table of the evolution of innovation management concepts is constructed. A new concept of innovation management is proposed taking into account the current state of the economy.

Keywords: innovative concepts, development, evolution, models, problems and solutions.

\section{Д.Ю. Салько \\ АНАЛИЗ РАЗВИТИЯ КОНЦЕПЦИЙ ИННО- ВАЦИОННОГО МЕНЕДЖМЕНТА}

В статье рассматриваются и анализируются различные концепции инновационного менеджмента в разные периоды времени. Выявляются их особенности, достоинства и недостатки. Строится хронологическая таблица эволюции концепций инновационного менеджмента. Предлагается новая концепция инновационного менеджмента с учётом современного состояния экономики.

Ключевые слова: инновационные концепции, развитие, эволюция, модели, проблемы и пути решения.

DOI: 10.36807/2411-7269-2021-2-25-26-31

Инновации имеют огромное значение в современной экономике, как для отдельной компании, так и для государства в целом. Инновации являются главным фактором создания условий высоких конкурентных преимуществ [1].

В связи с этим возрастает и роль инновационного менеджмента как механизма хозяйственного воздействия, который направлен на создание, продвижение и реализацию инноваций.

На протяжении своей истории инновационный менеджмент постепенно развивался. Данное развитие рассматривается в статье.

Рассматривая инновационный менеджмент, можно определить изменение его развития применительно к циклам экономической активности К. Жугляра - 10-летние циклы (Табл. 1) [2].

Таблица 1 - Эволюции концепций инновационного менеджмента [2], [5], [7]

\begin{tabular}{|c|c|c|}
\hline $\begin{array}{c}\text { Интервал вре- } \\
\text { мени }\end{array}$ & Название концепции & Описание концепции \\
\hline 1 & 2 & 3 \\
\hline 1900-1910-e & $\begin{array}{l}\text { Концепция научного управле- } \\
\text { ния }\end{array}$ & $\begin{array}{l}\text { Следуя теории Ф. Тейлора - увеличить эффектив- } \\
\text { ность производства возможно за счёт применения } \\
\text { новых знаний, которые можно заимствовать из раз- } \\
\text { ных научных областей }\end{array}$ \\
\hline 1910-1920-e & $\begin{array}{l}\text { Концепция ориентации на } \\
\text { инновационные изменения }\end{array}$ & $\begin{array}{l}\text { В основу входят пять изменений, которые относят к } \\
\text { инновациям по Й. Шумпетеру: } \\
\text { 1) применение новой техники и технологии; } \\
\text { 2) внедрение продукции с новыми свойствами; } \\
\text { 3) применение нового сырья в производстве; } \\
\text { 4) преобразования в организации производства; } \\
\text { 5) создание новых рынков сбыта продукции и } \\
\text { услуг }\end{array}$ \\
\hline
\end{tabular}

\footnotetext{
${ }^{1}$ Салько Д.Ю., доцент кафедры менеджмента и маркетинга, кандидат экономических наук, доцент; Федеральное государственное бюджетное образовательное учреждение высшего образования "Санкт-Петербургский государственный технологический институт (технический университет)", г. Санкт-Петербург

Salko D.Y., Associate Professor of the Department of Management and Marketing, PhD in Economics, Associate Professor; Federal State Budgetary Educational Institution of Higher Education "Saint-Petersburg State Technological Institute (Technical University)", Saint-Petersburg

E-mail: SalkoDmitriy@yandex.ru
} 
Продолжение таблицы 1

\begin{tabular}{|c|c|c|}
\hline 1 & 2 & 3 \\
\hline 1920-1930-e & $\begin{array}{l}\text { Концепция планирования по- } \\
\text { следовательности технологи- } \\
\text { ческих операций }\end{array}$ & $\begin{array}{l}\text { Создание и применение метода планирования и } \\
\text { организации последовательности операций по си- } \\
\text { стеме диаграммы Гантта }\end{array}$ \\
\hline 1930-1940-e & $\begin{array}{l}\text { Концепция научной организа- } \\
\text { ции рабочих мест за счёт учё- } \\
\text { та психологического фрактора в } \\
\text { трудовом процессе }\end{array}$ & $\begin{array}{l}\text { Использование результатов исследования Ф. Гил- } \\
\text { берт и Л. Гилберт трудовых движений и достижений } \\
\text { производственной психологии. Научная организация } \\
\text { рабочих мест }\end{array}$ \\
\hline 1940-1950-e & $\begin{array}{l}\text { Концепция координации про- } \\
\text { цессов производства }\end{array}$ & $\begin{array}{l}\text { Применение концепции координируемой сборочной } \\
\text { линии }\end{array}$ \\
\hline 1950-1960-e & $\begin{array}{l}\text { Концепция рационализации } \\
\text { управленческих решений }\end{array}$ & $\begin{array}{l}\text { Дж. Атанасов описал и построил первый цифровой } \\
\text { компьютер, что послужило началом многовариантно- } \\
\text { го решения крупных проблем с помощью автомати- } \\
\text { зации вычислений }\end{array}$ \\
\hline 1960-1970-e & $\begin{array}{l}\text { Концепция модели "техноло- } \\
\text { гического толчка" (technology } \\
\text { push) G1 }\end{array}$ & $\begin{array}{l}\text { Модель G1 представлялась в виде линейной после- } \\
\text { довательности циклично повторяющихся этапов } \\
\text { (Рис. 3) }\end{array}$ \\
\hline 1970-1980-e & $\begin{array}{l}\text { Концепция модели "рыночное } \\
\text { притяжение" (market pull) G2 }\end{array}$ & $\begin{array}{l}\text { По данной модели, коммерчески успешные нововве- } \\
\text { дения возникают как результат учёта запросов по- } \\
\text { требителей. Активно рассматривается рыночный } \\
\text { спрос, который задаёт направление научным иссле- } \\
\text { дованиям (Рис. } 4 \text { ) }\end{array}$ \\
\hline 1980-1990-e & 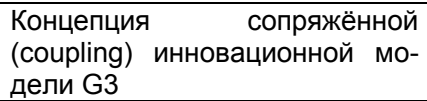 & $\begin{array}{l}\text { Данной модели уже присущи нелинейные процессы } \\
\text { создания нововведения (Рис. 5). }\end{array}$ \\
\hline 1990-2000-e & $\begin{array}{l}\text { Концепция интегрированной } \\
\text { инновационной модели G4 }\end{array}$ & $\begin{array}{l}\text { Решение проблем ускоряет слаженная работа не- } \\
\text { скольких специалистов в области исследований и } \\
\text { разработок, технического производства, финансов и } \\
\text { маркетинга. В конце идея должна быть проанализи- } \\
\text { рована специальной группой (Рис. 6) }\end{array}$ \\
\hline 2000-2010-e & $\begin{array}{l}\text { Концепция инновационной } \\
\text { модели стратегических сетей } \\
\text { G5 }\end{array}$ & $\begin{array}{l}\text { Концепция инновационной модели стратегических } \\
\text { сетей G5 содержит взаимодействие структур компа- } \\
\text { нии, поставщиков, потребителей и конкурентов. Ре- } \\
\text { зультатом взаимодействия является создание инно- } \\
\text { вации (Рис. 7) }\end{array}$ \\
\hline 2010-2020-e & $\begin{array}{l}\text { Концепция инновационной } \\
\text { модели инфоормационных тех- } \\
\text { нологий G6 }\end{array}$ & $\begin{array}{l}\text { Перемещение инновационного продукта от матери- } \\
\text { альной составляющей к интеллектуальной состав- } \\
\text { ляющей }\end{array}$ \\
\hline $\begin{array}{l}2020 \text {-е по насто- } \\
\text { ящее время }\end{array}$ & $\begin{array}{l}\text { Концепция прогнозирования с } \\
\text { применением } \\
\text { технологий }\end{array}$ & $\begin{array}{l}\text { Моделирование и прогнозирование становится ин- } \\
\text { струментом при принятии рациональных решений } \\
\text { как норма для всех инновационных компаний (Рис. 8) }\end{array}$ \\
\hline
\end{tabular}

- Фундаментальные исследования

• Прикладные исследования

3 - Опытно-конструкторские разработки

• Опытный образец

- Маркетинг

• Промышленный образец

- Производство

- Сбыт

Рис. 1 - Концепция модели "технологического толчка" (technology push) G1

На Рис. 2 в модели G2 толчком является рыночный спрос. По логике этой модели нововведение выгодно в том случае, если оно отвечает потребностям и желаниям потребителей. Спрос призван задавать тренд научным разработкам. После этого идёт опять линейный процесс, приведённый на Рис. 1. 


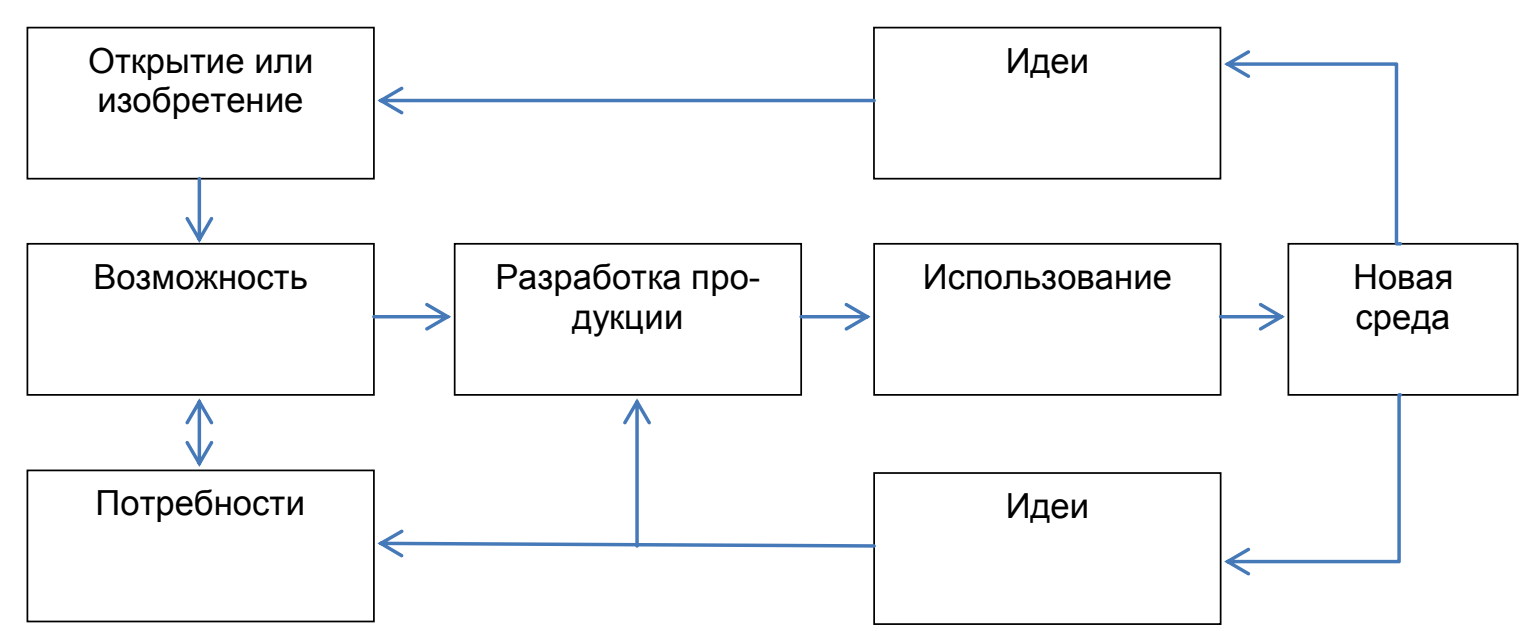

Рис. 2 - Концепция модели "рыночное притяжение" (market pull) G2

Недостаток модели G2 заключается в её линейной последовательности, которая происходит в нелинейном процессе. Применяя данную модели компании в 1970-1980 гг. существенно ограничивали свою инновационную деятельность, которая должна быть направлена на постоянный поиск нововведений.

Следующая концепция - концепция сопряжённой инновационной модели G3 появилась 1980-1990-е гг. В данной модели источником инновации одновременно служат НИОКР и потребности рынка (Рис. 3) [5], [6], [7].

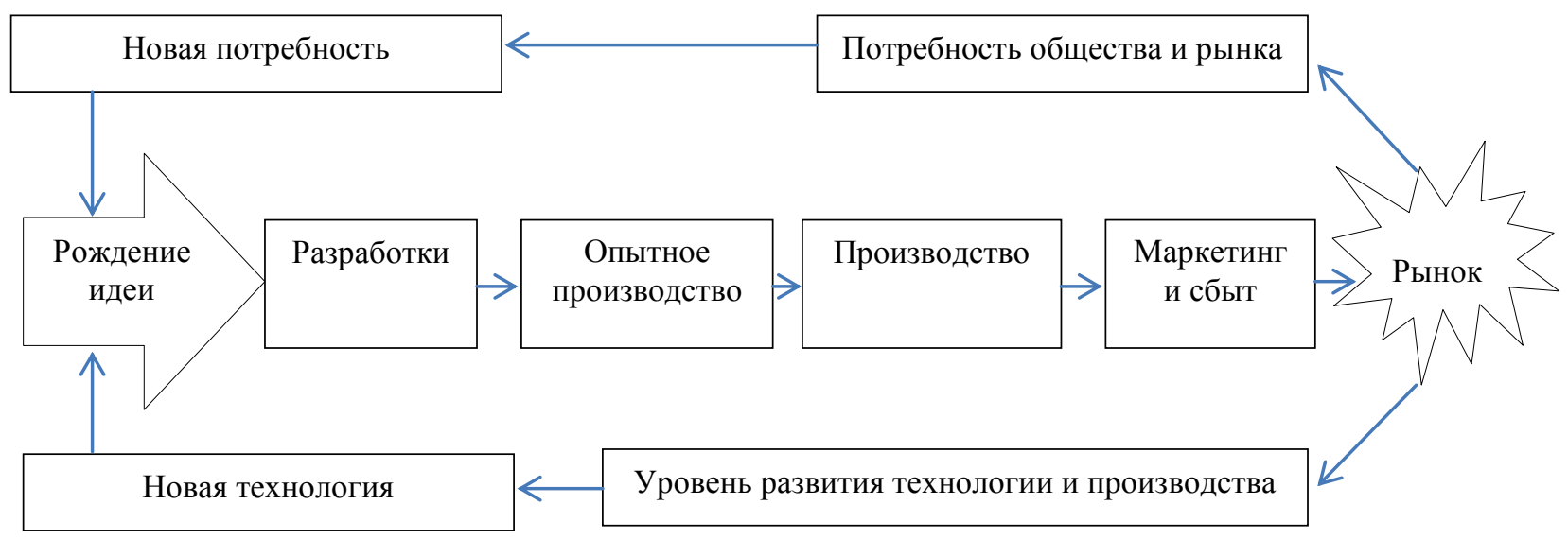

Рис. 3 - Концепция инновационной модели G3

Начиная с начала 1990-х гг. происходит дальнейшее развитие инновационных концепций, появляется японская инновационная модель G4. B ней большое внимание было сконцентрировано на сотрудничестве с покупателями и подразделениями в области маркетинга, фринансов, технологии. Задача производителей - заранее узнать отношение клиентов к инновациям и учесть это отношение в дальнейших разработках (Рис. 4). 


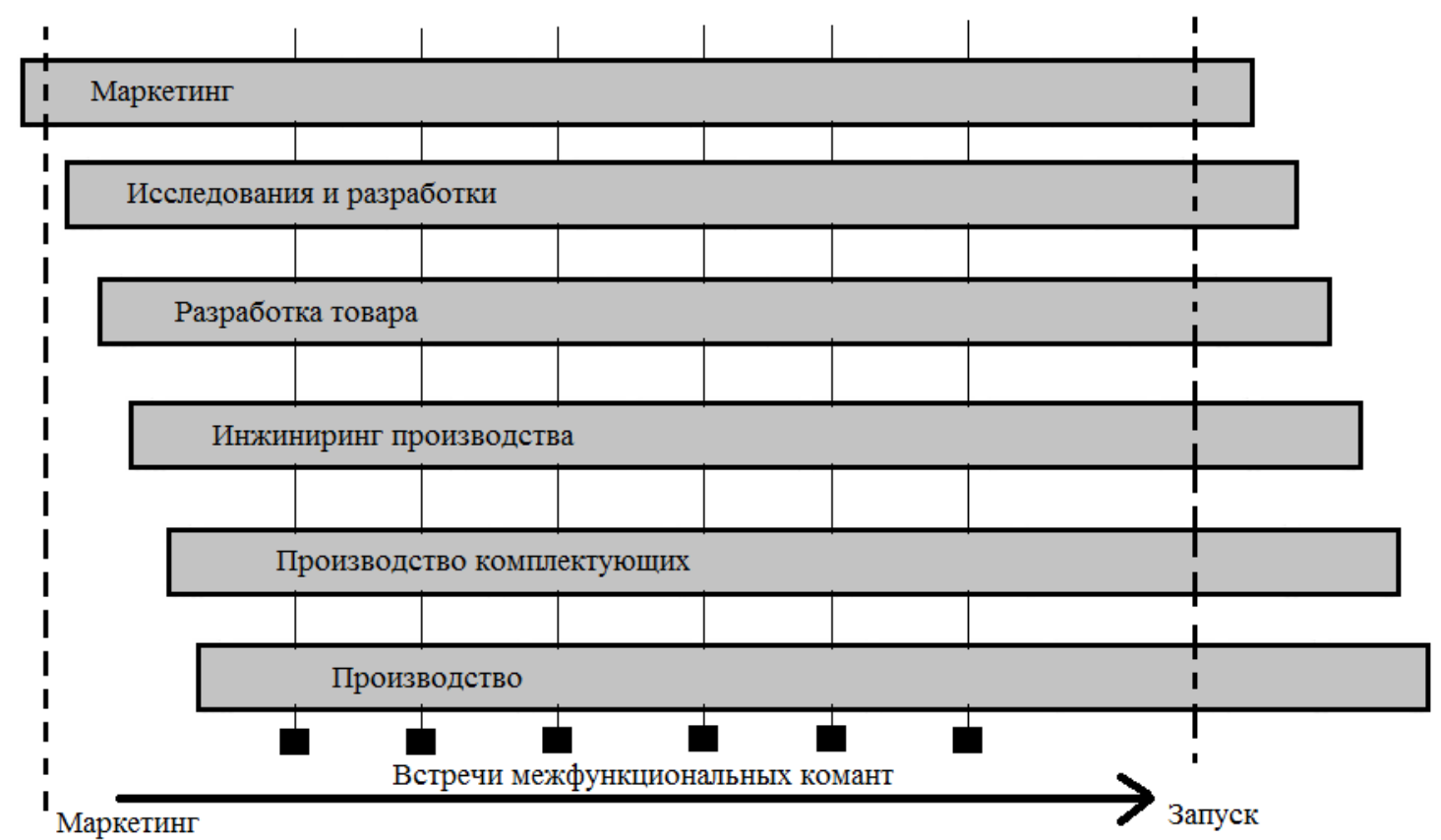

Рис. 4 - Концепция инновационной модели G4

В результате насыщения рынка, с начала 2000-х гг., происходит последующее ускорение инновационных процессов и возникает инновационная модель стратегических сетей $\mathrm{G5}$, в которой взаимодействуют разные институты, и как результат на выходе появляется инновация.

Сложность и затратность инновационного процесса требуют тщательного проведения исследований и разработок продукта. Поэтому до стадии разработки допускаются только те идеи, которые имеют определённые перспективы.

Подобный отбор идей можно представить на Рис. 5 (модель "Воронка") [3].

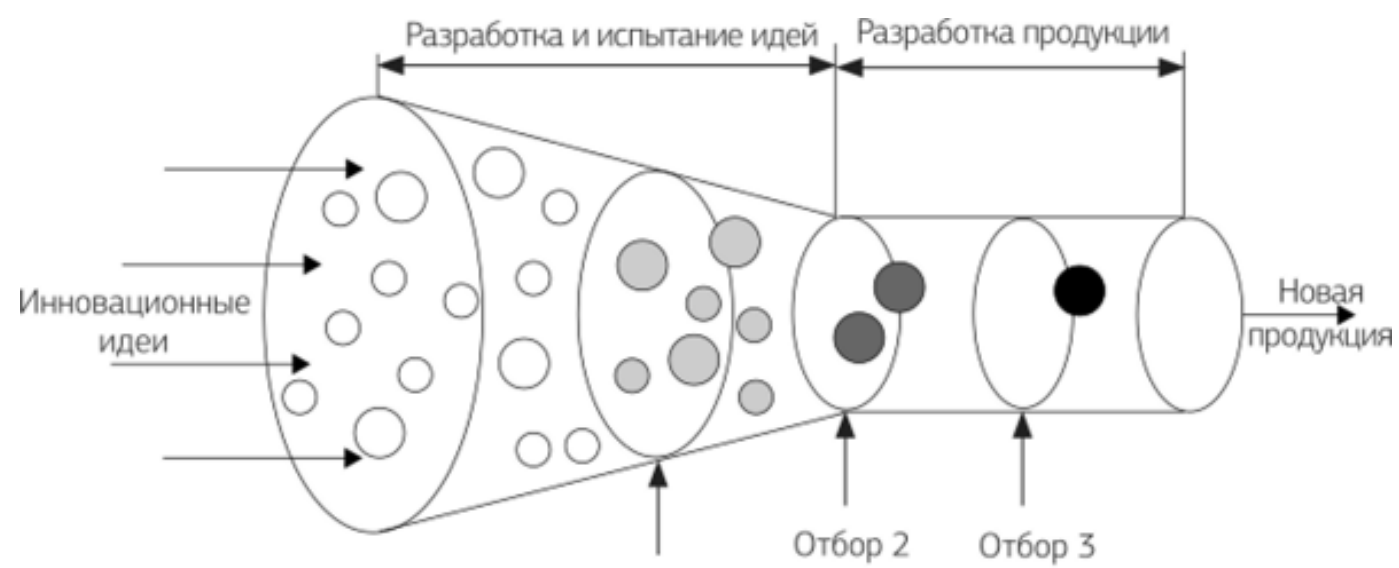

Рис. 5 - Концепция инновационной модели стратегических сетей G5 [3]

С появлением новых знаний, в результате взаимодействия стратегического партнёрства - новатора, организации и внешней среды, в 2010-е гг. появляется инновационная модель информационных технологий G6 [8], [9], [10].

По данной модели, затраты на разработку инновации сокращаются, поскольку активно применяется моделирование с помощью компьютерных технологий.

С 2020-х гг. по настоящее время всё большую актуальность приобретает не только моделирование, но и прогнозирование появления тех или иных инновационных продуктов. Организациям приходится искать путь для выживания в эпоху пандемии вирусов, политических санкций и нестабильности экономики. Моделирование и прогнозирование становится инструментом при принятии рациональных решений. 


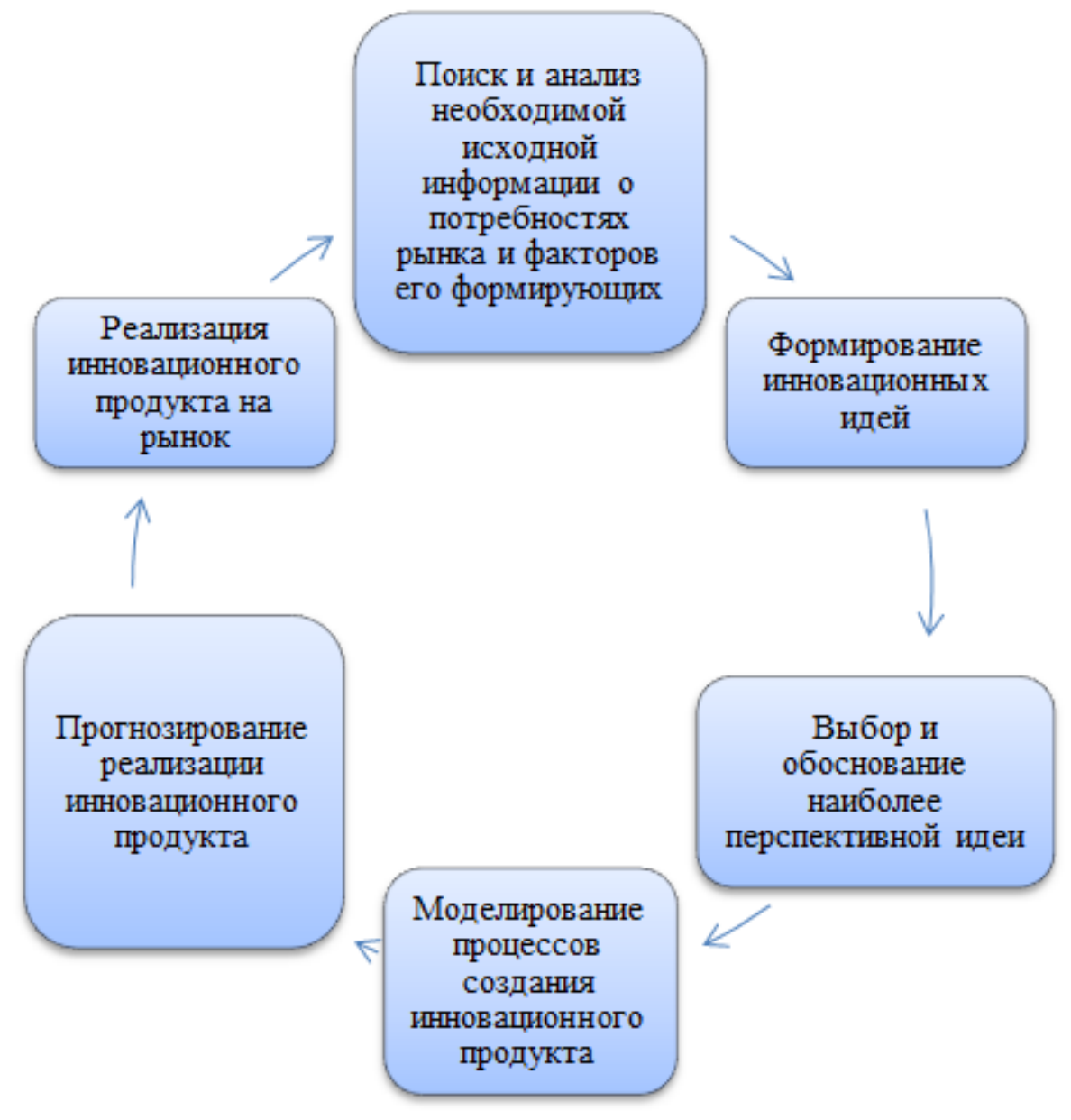

Рис. 6 - Концепция прогнозирования с применением современных технологий

Проанализировав эволюцию концепций инновационного менеджмента, можно сделать вывод, что в действительности все инновационные процессы в каждой отдельной организации реализуются с учётом специфики работы предприятий [4].

Представленные модели показывают лишь изменение восприятия об инновационных процессах в науке в соответствии с существующими тенденциями.

\section{Список использованных источников}

1. Салько Д.Ю., Кокорин И.А. "Эволюция концепции инновационной деятельности" // Научный журнал "Экономический вектор". - СПб: Издательство СанктПетербургского государственного технологического института (технического университета). - 2020. - № 4(23). - С. 72-76 (DOI: 10.36807/2411-7269-2020-4-23-72-76).

2. Тебекин А.В. Инновационный менеджмент: учебник для бакалавров / А.В. Тебекин. - 2-е изд., перераб. и доп. - М.: Издательство Юрайт, 2020. - 481 с. - Серия: Бакалавр. Базовый курс.

3. Баранчеев В.П. Управление инновациями: учебник для академического бакалавриата / В.П. Баранчеев, Н.П. Масленникова, В.М. Мишин. - 3-е изд., перераб. и доп. Москва: Издательство Юрайт, 2019. - 747 с. - (Высшее образование). - ISBN 978-5-53411705-9. - Текст: электронный // ЭБС Юрайт [сайт]. - URL: https://urait.ru/bcode/445971 (дата обращения: 26.04.2021).

4. Ставенко Ю.А., Громов А.И. Эволюция моделей управления инновационными процессами в организации // Бизнес-информатика. - 2012. - № 4(22). - С. 3-9.

5. Барышева А.В. Инновационный менеджмент: учебное пособие / А.В. Барышева. - 3-е издание. - М.: Дашков и К, 2012. - 384 с.

6. Никифоров И.К. Инновационная деятельность как фрактор развития экономических систем: автореф. дис... к. экон. н. / И.К. Никифроров; Вост.-Сиб. техн. ин-т. - Улан-Удэ, 2004. $-18 \mathrm{c}$. 
7. Шумпетер Й. Теория экономического развития / Й. Шумпетер. - М.: Прогресс, 1982. $-864 \mathrm{c}$.

8. Мухамедьяров А.М. Инновационный менеджмент: учебное пособие / А.М. Мухамедьяров. - М.: Инфра-М, 2008. - 176 с.

9. Шарин А.Н. Управление технологическими инновациями на предприятиях добывающих отраслей: на примере Нерюнгринского района Республики Саха (Якутия): автореф. дис... к. экон. н. / А.Н. Шарин; Ин-т. Управления и экономики. - Санкт-Петербург, 2004. -21 c.

10.Миропольский Д.Ю. Инновационные процессы социального экономического развития в новом тысячелетии. Модернизация - вектор современного социальноэкономического развития: монография / Д.Ю. Миропольский [и др.]. - М.: Экономика, 2011. - $716 \mathrm{c}$.

11.Маслюковская А. Инновационная теория Йозефра Шумпетера: от классического определения понятия "инновация" к современному пониманию инновационных идей // Вестник Киевского национального университета им. Тараса Шевченко. Серия: Экономика. - 2013. - № 145.

12.Чуева 3.И. О терминологии и классификации инноваций // Финансовая аналитика: проблемы и решения. - 2014. - № 16. 